\title{
Editorial
}

\section{Perspectives on trends in mortality and case fatality from coronary heart attacks: the need for a better definition of acute myocardial infarction}

In this issue Norris and colleagues contrast their cardiological perspective of coronary heart disease mortality in 1994-95 in Brighton, South Glamorgan, and York with statistics based on death certificates. ${ }^{1}$ They also compare coronary event rates and case fatality with British studies from the 1960 s and 1970s, and with data from 1985-87 from 38 WHO MONICA project populations worldwide, including Belfast and Glasgow. ${ }^{2}$

Designation of their three centres in England and Wales as the United Kingdom heart attack study (UKHAS) seems immodest in view of activity elsewhere ${ }^{2}$ but they do provide data from areas of the UK missing from the 10 year MONICA project. MONICA, although drafted in London in 1979-81, ${ }^{4}$ despite later regrets, evinced little local interest in the funding of an English or Welsh centre, leaving Scotland and Northern Ireland supporting the initiative. Given the separateness of UKHAS and the authors' emphasis on cardiology versus epidemiology, how has it fared, and how comparable is it with other heart attack registers?

Coronary heart attack registration involves mixing fatal and non-fatal attacks. Manipulation of diagnostic criteria produces an astonishing range of results for attack rate and case fatality. ${ }^{5}$ Naive clinicians and politicians believe that survival rates mirror treatment alone, but the recent advent of performance indicators and league tables ${ }^{6}$ has brought the cynical realisation that much can be done through massaging diagnostic criteria.

Case fatality - the percentage of deaths at 28 days (WHO) or 30 days (UKHAS) - depends on numbers of fatal and non-fatal events, which together constitute the attack rate. Low case fatality results from non-specific criteria for non-fatal events but selective criteria for fatal events; high case fatality results from mixing very specific criteria for non-fatal events with unselected fatalities.

Numbers of potential coronary deaths in a population are finite, $70 \%$ or so occur suddenly outside hospital and only half are associated with previous angina or infarction. ${ }^{7}$ Heart attack registers are subject to local rules on medical confidentiality and medicolegal practice, which determine whether a coronary diagnosis is pursued to postmortem examination or left to the inspired guess of a medical practitioner or lawyer. While the UKHAS team scrutinised coronary deaths as if vetting applicants to join an exclusive club, the WHO MONICA project included not only definite and possible coronary deaths, but also "unclassifiable" deaths. ${ }^{2}$ In these, whatever informed the completion of the death certificate, there was no relevant diagnostic data available to the survey team. As well as the recruitment in some centres (for example, France) of many deaths as potential coronaries that were certified differently, the inclusion of the unclassifiable cases appeared to balance case fatality across centres, so inclusive criteria made empirical sense, however questionable in individual cases. Although causes of unexplained sudden death other than coronary disease are comparatively rare, there would be benefits from better international standardisation in medi- colegal and death certification practice. They retain an unfortunate and undeserved 19th century aura of professional inviolability, which antedates modern concepts of quality control, audit, and accountability.

Non-fatal myocardial infarction has different problems. Definite infarction shades off into what Americans call "rule out" myocardial infarction and unstable angina, and there is a variable proportion of silent and misdiagnosed cases. ${ }^{8}$ Diagnostic criteria are so well known that clinicians would be aghast at having their competence questioned. Yet different diagnostic thresholds in mild cases affect numbers of events and therefore event rates and case fatality.

The WHO European office myocardial infarction registers of the 1960s used loose criteria describing chest pain and electrocardiographic progression, which, with levels of cardiac enzymes, categorised infarcts as definite or possible, the two categories being combined for collaborative reporting. ${ }^{9}$ WHO criteria for non-fatal myocardial infarction were re-examined in 1981 in preparation for the WHO MONICA project. The 1960 s criteria lacked specificity and were redefined quantitatively using Minnesota ECG codes. ${ }^{2}$ It was decided that the end point for monitoring non-fatal events would be "definite" myocardial infarction. Although this excluded many mild coronary episodes and attracted criticism as being too specific $^{10-12}$ it correlated well with patients subsequently receiving thrombolytic treatment. Standardisation of criteria and methods in the WHO MONICA project was facilitated by setting up quality control centres for ECG coding in Budapest and for event registration in Dundee. These carried out workshops, training, and external quality control, aided by funding from WHO and the National Heart, Lung, and Blood Institute in Washington. ${ }^{13}$

In contrast, UKHAS used the two of three criteria (history and/or sequential ECG changes-not coded quantitatively - and/or raised cardiac enzymes) often attributed by clinicians to WHO, and said to correspond to clinical diagnosis. A member of the steering committee visited centres to audit a random selection of cases.

Although UKHAS asserts that its non-fatal cases were equivalent to the definite and possible cases registered in the (first generation WHO) East London register, ${ }^{14}$ it also claims that they equate to MONICA definites. ${ }^{1}$ The first generation European registers experienced a 28 day case fatality of $35 \%$ involving non-fatal definites and possibles. ${ }^{9}$ For MONICA in the 1980s, using the main diagnostic grouping confined to definite non-fatal cases, case fatality averaged $49 \%$ in men and $54 \%$ in women; this drops to $39 \%$ and $38 \%$ if non-fatal possibles are added, emphasising the importance of the diagnostic criteria. ${ }^{2}$ UKHAS case fatality was $35 \%$ in men and $36 \%$ in women when standardised to MONICA age weighting, suggesting that their non-fatal criteria were more similar to the first generation WHO register definites and possibles than to MONICA definites. 
This analysis in no way invalidates the UKHAS results, which are mainly focused on fatal cases, ${ }^{1}$ but it illustrates the pitfalls of coronary event registration if undue faith were placed in the consistency of clinical diagnosis of myocardial infarction. If the MONICA definite category is used as a standard, the 38 centres worldwide differ considerably as to how well their clinical diagnoses of myocardial infarction correspond in sensitivity and positive predictive value. ${ }^{2}$ Minnesota coding is difficult, time consuming, and subject to observer variation. ${ }^{15}$ Biochemical tests such as cardiac enzymes are not standardised well enough to use as a gold standard test. Yet interest in coronary disease monitoring and in-hospital performance indicators reinforces the need for a new standard definition of myocardial infarction. Rather than going back from the difficult 1980s MONICA definition of myocardial infarction to the 1960s WHO clinical description, we should be going forward to something more precise and workable for general use in the next century perhaps involving specific methods of myocardial injury. ${ }^{16}$

HUGH TUNSTALL-PEDOE WHO MONICA Project Quality Control Centre for Event Registration, Cardiovascular Epidemiology Unit, Ninewells Hospital and Medical School, Dundee DD1 9SY, UK

1 The United Kingdom Heart Attack Study (UKHAS) Collaborative Group. The falling mortality from coronary heart disease: a clinicopathological perspective. Heart 1998;80:121-6.

2 Tunstall-Pedoe H, Kuulasmaa K, Amouyel P, et al, for WHO MONICA Project. Myocardial infarction and coronary deaths in the World Health
Organisation MONICA Project-registration procedures, event rates, and case fatality rates in 38 populations from 21 countries in 4 continents. Circase fatality rates in 38 pop
culation 1994:90:583-612.

3 Brown N, Young T, Gray D, et al. Inpatient deaths from acute myocardial infarction in 1982-92: analysis of data in the Nottingham heart attack register. BMF 1997;315:159-64.

4 Tunstall-Pedoe $\mathrm{H}$. Monitoring trends in cardiovascular disease and risk factors: the WHO "MONICA" project. WHO Chronicle 1985;39:3-5.

5 Tunstall-Pedoe $\mathrm{H}$. Uses of coronary heart attack registers. Br Heart $\mathcal{F} 1978$; 40:510-15.

6 Leyland AH, Boddy FA. League tables and acute myocardial infarction. Lancet 1998;351:555-8.

7 Tunstall-Pedoe H, Morrison C, Woodward M, et al. Sex differences in myocardial infarction and coronary deaths in the Scottish MONICA population of Glasgow 1985-91: presentation, diagnosis, treatment and 28 -day case fatality of 3991 events in men and 1551 events in women. Circulation 1996;93:1981-92.

8 Grimm RH, Tillinghast S, Daniels $\mathrm{K}$, et al. Unrecognised myocardial infarction: experience in the multiple risk factor intervention trial (MRFIT). Circulation 1987;75(suppl II):6-89.

9 World Health Organization Regional Office for Europe: Myocardial Infarction Community Registers. Public health in Europe. No 5. Copenhagen, WHO, 1976

10 Beaglehole R, Stewart A, Butler M. Comparability of old and new World Health Organisation criteria for definite myocardial infarction. Int 7 Epidemiol 1987;16:373-6.

11 Martin CA, Hobbs MST, Armstrong BK. Measuring the incidence of acute myocardial infarction: the problem of possible acute myocardial infarction. Act Med Scand 1988;(suppl 728):40-7.

12 Salomaa V, Dobson A, Miettinen H, et al, for WHO MONICA Project. Mild myocardial infarction - a classification problem in epidemiological studies. f Clin Epidemiol 1997;50:3-13.

13 Tunstall-Pedoe H. Diagnosis, measurement and surveillance of coronary events. Int F Epidemiol 1989;18(suppl 1):S169-73.

14 Tunstall-Pedoe H, Clayton D, Morris JN, et al. Coronary heart attacks in East London. Lancet 1975;ii:833-8.

15 Prineas RJ, Crow RS, Blackburn H. The Minnesota code manual of electrocardiographic findings. Standards and procedures for measurement and diographic findings. Standards and proct
classification. Boston: John Wright, 1982.

16 Mercer DW. Role of cardiac markers in evaluation of suspected myocardial infarction: selecting the most useful clinical indicators. Postgrad Med $\mathcal{F}$ 1997;102:113-17. 